\section{Optical coherence
tomography for the \\ Optical coherence
tomography for the diagnosis of neovascular age- related macular degeneration: a systematic review}

MM Castillo' ${ }^{1}$ G Mowatt ${ }^{1}$, N Lois², A Elders ${ }^{3}$, C Fraser ${ }^{1}$, W Amoaku ${ }^{4}$, JM Burr ${ }^{5}$, AJ Lotery ${ }^{6}$, CR Ramsay ${ }^{1}$ and A Azuara-Blanco ${ }^{2}$

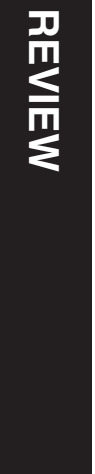

${ }^{1}$ Health Services Research Unit, University of Aberdeen, Scotland, UK

Eye (2014) 28, 1399-1406; doi:10.1038/eye.2014.214; published online 19 September 2014

\section{Introduction}

Anti-vascular endothelial growth factor (VEGF) therapies have revolutionised the treatment of neovascular age-related macular degeneration (nAMD). Visual outcomes following antiVEGF $^{1-4}$ have been unparalleled by previous therapies which included laser photocoagulation ${ }^{5,6}$ and photodynamic therapy. ${ }^{7}$ The cost-effectiveness of anti-VEGF drugs depends, however, on the establishment of an early and accurate diagnosis. Fundus fluorescein angiography (FFA) interpreted by an ophthalmologist is the current reference standard for the diagnosis of nAMD, ${ }^{8,9}$ as it directly detects the presence of the neovascular tissue that fills with the dye. However, FFA is an invasive and a timeconsuming test. Other alternative diagnostic technologies are available of which the most widely used is optical coherence tomography (OCT). OCT, including time-domain (TD-OCT) and the most recently developed spectral domain (SD-OCT), is a lightwave-based technology that allows the imaging of the retina obtaining 'sections' of this neovascular tissue with scan rates and resolution parameters that have greatly improved over the past 10 years. OCT is a non-invasive, non-contact visual test that requires about 5-10 min to assess both eyes. It is user friendly, typically undertaken by trained medical photographers and interpreted

\section{${ }^{2}$ Centre for Vision and Vascular Science, Queen's University Belfast, Belfast, UK \\ ${ }^{3}$ Glasgow Caledonian University, Glasgow, UK \\ ${ }^{4}$ University of Nottingham, Nottingham, UK \\ ${ }^{5}$ University of St Andrews, St Andrews, UK \\ 'University of Southampton, Southampton, UK \\ Correspondence: A Azuara-Blanco, Department of Ophthalmology, Queen's University Belfast, Belfast BT12 6BA, UK or Institute of Clinical Science - Block A, Grosvenor Road, Belfast BT12 6BA, UK Tel: +44 (0)28 9063 2636; Fax: +44 (0)289063 2699. E-mail: a.azuara-blanco@ qub.ac.uk}

Received: 8 May 2014 Accepted in revised form: 12 August 2014 Published online: 19 September 2014

Poster presented at ARVO annual meeting 2013. 
by ophthalmologists. However, it might also lead to efficiencies by allowing other categories of health professionals to become involved in the diagnosis of patients.

The aim of this systematic review was to evaluate the diagnostic accuracy, interpretability, and acceptability of OCT, alone or in combination with other tests, for the assessment of newly presenting patients suspected of having $\mathrm{nAMD}$.

\section{Materials and methods}

The index test performed was OCT. Both TD-OCT and SD-OCT were considered. Comparator tests were clinical evaluation with slit lamp biomicroscopy (with or without the use of contact lens), visual acuity, Amsler grid, colour fundus photography, infra-red reflectance, red-free images, fundus autofluorescence imaging (FAF), indocyanine green angiography (ICGA), preferential hyperacuity perimetry (PHP), and microperimetry. The reference standard was FFA interpreted by an ophthalmologist. However as few studies reported individual ophthalmologist-interpreted FFA (rather than reading centre-interpreted FFA), studies using FFA as the reference standard but with unclear information about which type of healthcare professionals interpreted the images were also considered. Participants were individuals presenting with symptoms of nAMD. Types of studies considered were direct (head-to-head) comparisons, in which all the participants received the index test and the reference standard, and indirect comparisons (eg, case-control studies) in which estimates of the accuracy of the respective tests were obtained in different study groups. Randomised controlled trials (RCTs) evaluating effectiveness outcomes where treatment was based on OCT compared with FFA findings were also included, as were the studies evaluating the acceptability and/or interpretability of the test.

Published, unpublished, and ongoing studies were identified from literature searches of electronic databases (from 1995 to March 2013) and appropriate websites. There were no language restrictions. Databases searched included MEDLINE, MEDLINE In-Process, EMBASE, Biosis, and Science Citation Index for all reviews (see Supplementary Appendix 1). The Cochrane Central Register of Controlled Trials was searched for additional reports on RCTs reporting effectiveness outcomes and PsycINFO and ASSIA for studies reporting acceptability data. The Cochrane Database of Systematic Reviews, Database of Abstracts of reviews of Effects, MEDION, and HTA database were searched for relevant systematic reviews and HTA reports. Abstracts and presentations from recent conferences (from January 2009 to September 2012) of the American Academy of Ophthalmology, the Association for Research in Vision and Ophthalmology, and the European Association for Vision and Eye Research and also the WHO International Clinical Trials Registry Platform, Clinical Trials.gov, and EU Clinical Trials Register were searched for ongoing studies. Websites of key journals, professional organisations, and manufacturers of equipment were also consulted. Reference lists of all the included studies were also evaluated for possible inclusion and authors were contacted for details of additional potentially relevant reports.

Two reviewers independently screened the titles and abstracts (if available) of all the reports identified by electronic searches. Full-text copies of all potentially relevant papers were obtained and two reviewers independently assessed them for inclusion. Data extraction was undertaken by one reviewer (MMC) and checked by a second (AAB or GM). The risk of bias and applicability concerns of included full-text studies was assessed by two reviewers independently using an adapted version of the updated quality assessment of diagnostic accuracy studies (QUADAS-2) checklist. ${ }^{10}$ This checklist is designed to be adapted to the specific review topic. Disagreements were resolved by consensus or arbitration by a third reviewer.

The results of the individual studies were tabulated and, when possible, sensitivity, specificity, predictive values, likelihood ratios, and diagnostic odds ratios (DORs) were calculated. Summary receiver operating characteristic (SROC) curves were produced for each test where two or more diagnostic studies provided sufficient data. Meta-analysis models were fitted using the hierarchical summary receiver operating characteristic (HSROC) model $^{11}$ in SAS version 9.1 (SAS Institute Inc., Cary, NC, USA). A symmetric SROC model was used, which takes proper account of the diseased and non-diseased sample sizes in each study, and allows estimation of random effects for the threshold and accuracy effects. The SROC curves from the HSROC models were produced on the corresponding SROC plots. Summary sensitivity, specificity, positive and negative likelihood ratios, and DORs for each model were reported as point estimate and 95\% confidence interval (CI).

\section{Results}

A total of 4682 titles and abstracts were identified, of which 179 reports were selected for full-text assessment. Twenty-two studies (24 reports $^{12-35}$ ) met the inclusion criteria. One-hundred and fifty-five reports were excluded as they failed to meet one or more of the inclusion criteria in terms of study objective and design, participants, test, and reference standard or outcomes reported (Figure 1). 


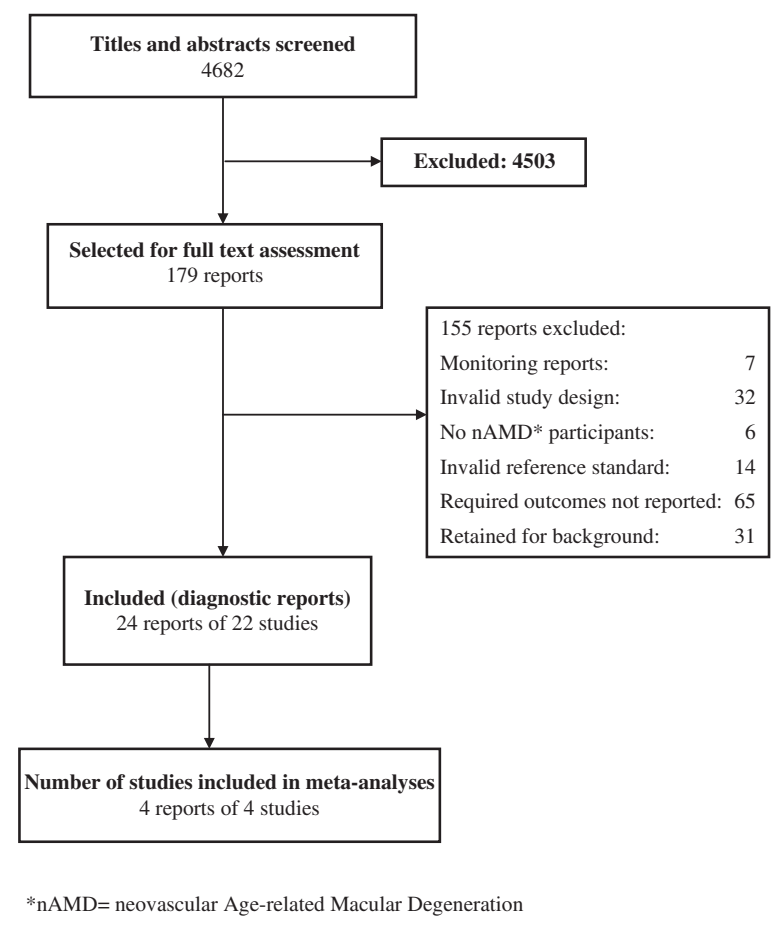

Figure 1 Flow diagram outlining the screening process.

Of the 22 included studies, 7 were retrospective, 9 were prospective, and 1 study $^{24}$ had both a prospective and retrospective component; the remainder did not provide this information. The studies enrolled 2124 participants, of which a total of 1754 eyes with suspected nAMD were available for analysis. In 10 studies, the participant recruitment was consecutive. A summary of the characteristics of the included diagnostic studies is presented in Table 1.

Twenty studies were full-text papers and two were available as abstracts. ${ }^{19,27}$ Four studies (five reports) were written in non-English languages (Fujii 1996 (Japanese), ${ }^{16}$ Chen 2003 (Chinese), ${ }^{14}$ Krebs 2007 (German), ${ }^{22}$ and Torron 2001 and Torron 2002 (Spanish)). ${ }^{34,35}$ Four studies reported the diagnostic performance of more than one test within the same population (Cachulo 2011 reported TD-OCT, ICGA, and FAF; ${ }^{13}$ Do 2012 reported TD-OCT, Amsler grid and PHP; 15 Alster 2005 reported PHP, colour fundus photography and visual acuity; ${ }^{12}$ Sandhu 2005 reported TD-OCT plus colour fundus photography ${ }^{30}$ ). The prevalence of $\mathrm{nAMD}$ in these studies ranged from 17.2 to $100 \%$ (median $80.0 \%$ ).

All of the studies reported the eye as the unit of analysis (1754 eyes) except for one study where the unit of analysis was the patient (155 patients). ${ }^{27}$

Regarding the risk of bias (Figure 2), the domains with the greatest number of studies judged to be at high risk of bias were the patient selection domain (55\%, $11 / 20$ ) for reasons such as inappropriate exclusions and
Table 1 Summary of the characteristics of the included diagnostic studies

\begin{tabular}{lcc}
\hline Characteristic & Number & $\begin{array}{c}\text { Number of } \\
\text { studies }\end{array}$ \\
\hline Participants enrolled & 2124 & 22 \\
Analysed (eyes) & 1754 & 21 \\
Analysed (patients) & 155 & 1 \\
Age: median (range) of means/medians & $76(51.4$ to 84.6$)$ & 15 \\
Gender, male:female n (\%) & $742(45.4 \%): 891(54.6 \%)$ & 14 \\
Median (range) prevalence of nAMD & $80.0 \%(17.2$ to $100 \%)$ & 13 \\
& & \\
Tests reported (number enrolled) & 1335 & 13 \\
OCT & 1316 & 12 \\
TD-OCT & 19 & 1 \\
SD-OCT & 458 & 8 \\
ICGA & 491 & 3 \\
PHP & 185 & 1 \\
Colour fundus photography & 98 & 1 \\
Amsler grid & 62 & 1 \\
FAF & &
\end{tabular}

Abbreviations: FAF, fundus autofluorescence imaging; ICGA, indocyanine green angiography; nAMD, neovascular age-related macular degeneration; OCT, optical coherence tomography; PHP, preferential hyperacuity perimeter; SD-OCT, spectral domain OCT; TD-OCT, time domain OCT.

pre-selection of participants, and the flow and timing domain $(40 \%, 8 / 20)$ for reasons such as the length of time between the index test and reference standard being longer than one week, and not all participants being included in the analysis. None of the studies were judged to have low risk of bias across all the domains. All reports were judged to have low concerns for applicability, in that the participants and setting, index/ comparator test and target condition as defined by the reference standard were considered to match the question being addressed by the review.

Regarding the diagnostic performance of OCT, Figure 3 shows a forest plot of the sensitivity and specificity of 10 studies. Across these studies, the median (range) sensitivity and specificity values reported were 94.5\% (36-100\%) and 73.5\% (66-94\%), respectively. Only four studies (all TD-OCT) reported specificity. For TDOCT, across the studies, the median (range) sensitivity and specificity values reported were 92.3\% (36-100\%) and $73.4 \%$ (66-94\%), whereas the only SD-OCT study reported sensitivity of $100 \%$ and did not report specificity. Four studies, all TD-OCT, provided sufficient data for inclusion in a meta-analysis, using HSROC methodology thus results are presented in Figure 4 and pooled estimates for these studies are shown in Table 2. The pooled sensitivity and specificity $(95 \% \mathrm{CI})$ were $88 \%$ (46-98\%) and 78\% (64-88\%), respectively. The metaanalysis findings are broadly supported by the descriptive analyses involving a larger number of studies, shown in Figure 3.

In descriptive analyses, across the studies reporting other tests, median sensitivity was high for ICGA (93.2\%, 
range 84.6-100\%; four studies) and FAF (93.3\%; one study), followed by PHP (81.5\%, range 50.0-84.8\%; three studies), colour fundus photography (70\%; one study), and lowest for Amsler grid (41.7\%, one study). Specificity was highest for colour fundus photography (95\%; one study), followed by PHP ( 84.6 and $87.7 \%$; two studies), and was low for FAF (37.1\%; one study) and ICGA (36.8\%; one study). Figure 5 shows a forest plot of the sensitivity and specificity of the PHP and ICGA studies, respectively.

Six studies provided some information related to the interpretability of the tests, in which they reported numbers excluded from the analysis due to poor image quality. ${ }^{12,13,15,21,24,30}$ For studies reporting OCT, the percentages of images excluded from analysis were $2.7 \%$ $(35 / 1307$ eyes $),{ }^{21} 5.8 \%(6 / 104),{ }^{15}$ and $7.8 \%(10 / 128$

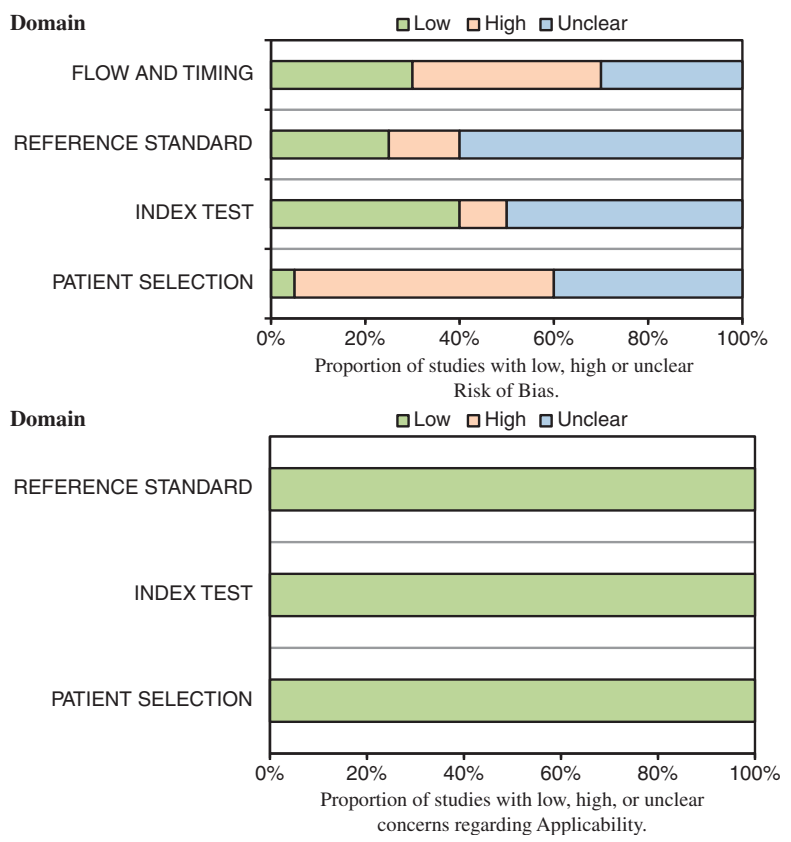

Figure 2 Summary of the risk of bias and applicability domains. individuals $)^{30}$ although it was unclear whether all of the excluded images related to OCT or whether some might also relate to FFA.

\section{Discussion}

We identified a relatively small body of evidence comparing OCT and other tests with a reference standard of FFA for the diagnosis of nAMD. The majority of studies reported TD-OCT (12 studies) and only one study reported SD-OCT therefore meta-analysis was possible only for TD-OCT. The pooled sensitivity for TD-OCT was relatively high at $88 \%$ and moderate specificity at $78 \%$. There was insufficient information to compare performance of different diagnostic technologies, or to address the acceptability of the tests, or clinical effectiveness when treatment was based on OCT compared with FFA findings, and little information was available on interpretability of the tests.

Descriptive analyses involving a larger number of studies broadly supported the meta-analyses findings. Of the alternative tests, median sensitivity was similarly high for ICGA $(93.2 \%, 4$ studies) and FAF (93.3\%, 1 study), followed by PHP (81.5\%, 3 studies) and colour fundus photography $(70.0 \%, 1$ study) but low for the Amsler Grid (41.7\%, 1 study). Specificity was highest for colour fundus photography (95\%, 1 study), followed by PHP (84.6 and $87.7 \% ; 2$ studies), and was low for FAF ( $37.1 \% ; 1$ study) and ICGA $(36.8 \% ; 1$ study). Our study is a systematic diagnostic accuracy review following robust methods and not limited to studies reported in English. A HSROC model was used for the analysis, which takes account of the trade-off between true/false positives and models between-study heterogeneity. ${ }^{36}$ Pooled estimates for TD-OCT were derived but were not possible for SDOCT due to insufficient data. There was also insufficient information to address the questions of the clinical effectiveness of OCT compared with FFA, or the acceptability of the tests.

Study
Cachulo 2011 (TD)
Do 2012 (TD)
Hughes 2005 (TD)
Kim 2003 (TD)
Kozak 2008 (TD)
Padnick-Silver 2011 (TD)
Park 2010 (SD)
Salinas-Alaman 2005 (TD)
Sandhu 2005 (TD)
Talks 2007 (TD)

$\begin{array}{rrrr}\text { TP } & \text { FP } & \text { FN } & \text { TN } \\ 17 & 0 & 0 & 0 \\ 6 & 21 & 9 & 51 \\ 8 & 0 & 14 & 0 \\ 12 & 0 & 1 & 0 \\ 514 & 0 & 14 & 0 \\ 12 & 4 & 3 & 58 \\ 21 & 0 & 0 & 0 \\ 60 & 0 & 2 & 0 \\ 63 & 12 & 18 & 38 \\ 73 & 13 & 0 & 25\end{array}$

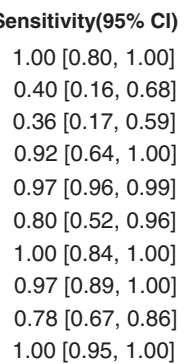

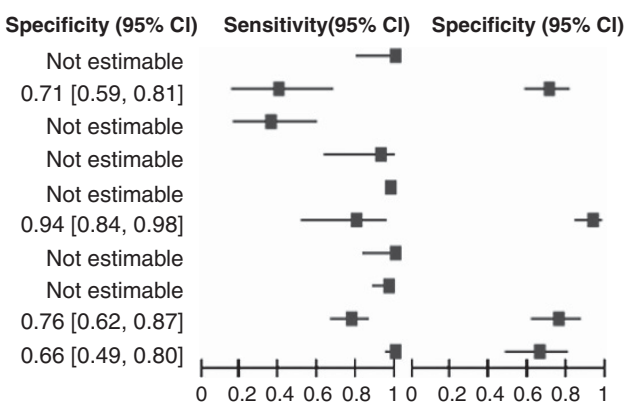

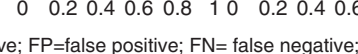

$\mathrm{OCT}=$ optical coherence tomography; $\mathrm{TD}=$ time domain; $\mathrm{SD}=$ spectral domain; $\mathrm{TP}=$ true positive; $\mathrm{FP}=$ false positive; $\mathrm{FN}=$ false negative; $\mathrm{TN}=$ true negative; $\mathrm{Cl}=$ confidence interval

Figure 3 Individual study results for all OCT diagnostic studies reporting sensitivity and/or specificity. 

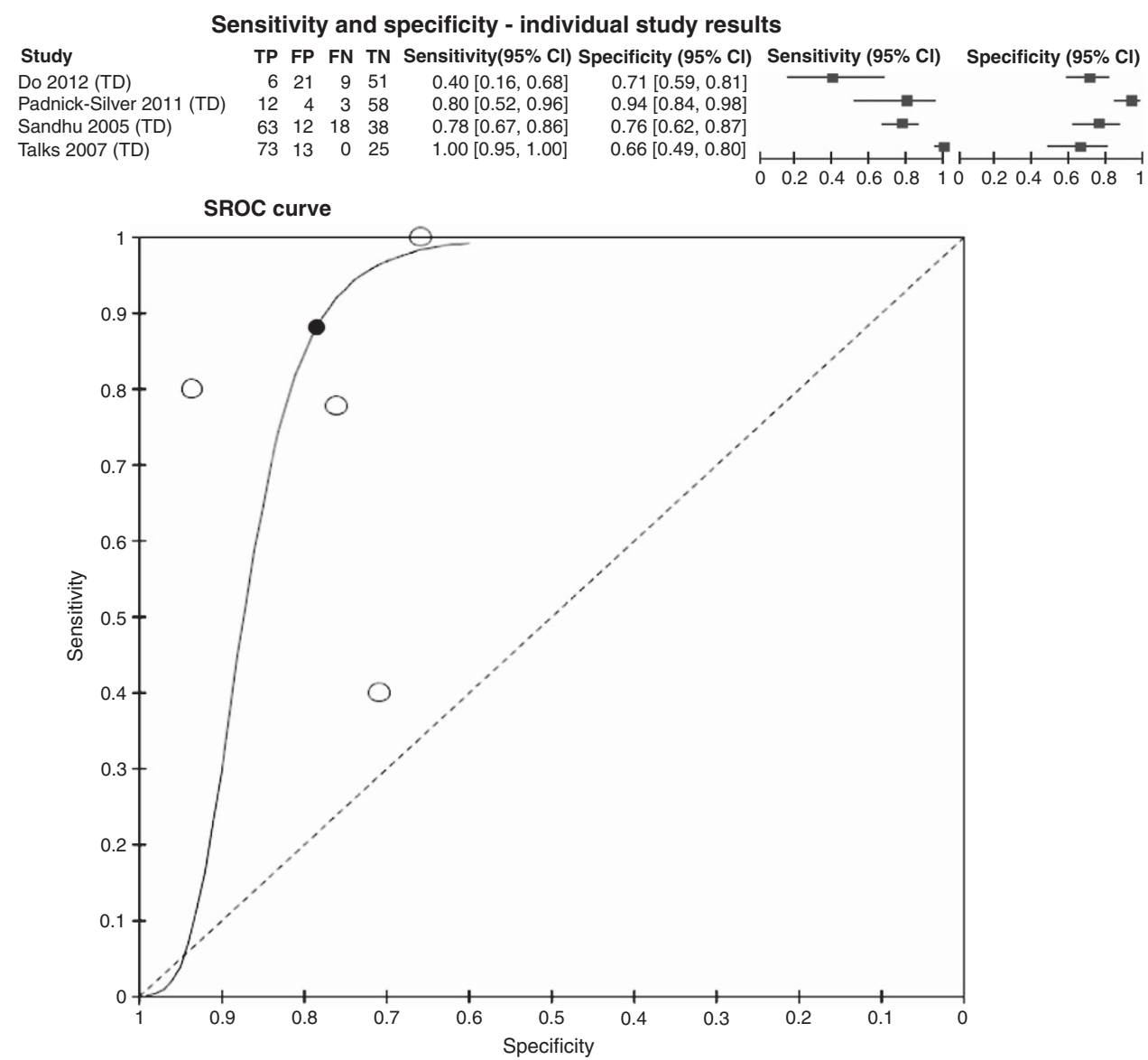

Figure 4 Individual study results reporting sensitivity and specificity for TD-OCT.

Table 2 Pooled estimates for the OCT diagnostic studies

\begin{tabular}{|c|c|c|c|c|c|c|c|}
\hline \multirow[t]{2}{*}{ Test } & \multirow{2}{*}{$\begin{array}{l}\text { Number of } \\
\text { studies }\end{array}$} & \multirow{2}{*}{$\begin{array}{c}\text { Number of eyes } \\
\text { analysed }\end{array}$} & \multicolumn{5}{|c|}{ Pooled estimates (95\% CI) } \\
\hline & & & Sensitivity & Specificity & $L R+$ & $L R-$ & DOR \\
\hline All OCT & 4 & 406 & $0.88(0.46,0.98)$ & $0.78(0.64,0.88)$ & $4.08(2.37,7.04)$ & $0.15(0.02,0.98)$ & $26.86(3.36,214.81)$ \\
\hline
\end{tabular}

FFA interpreted by an ophthalmologist was the reference standard test for our study, assuming perfect sensitivity and specificity. Consequently it was not possible to address the question of whether OCT might actually be a better diagnostic test than FFA and have higher sensitivity or specificity than the current reference standard. One approach that has been suggested for determining when a new test should replace the reference standard is that proposed by Glasziou et al. ${ }^{37}$ Glasziou et al suggested the use of a third, 'fair umpire' test, which although potentially less accurate than either the new test or the reference standard, nevertheless could be considered a fair umpire if its errors were considered to be independent of the other tests. ${ }^{37}$ However, the authors acknowledged that this would usually be difficult to demonstrate. Unfortunately, none of the included OCT studies involving a third test provided a sufficient level of detail to allow us to explore this approach.

In two studies, ${ }^{21,28}$ some participants were classified as having $\mathrm{nAMD}$ who were negative on FFA but positive on one of the other tests being assessed (13/541 eyes by TDOCT in the Kozak 2008 study and 4/20 participants by ICGA in the Reichel 1995 study). For the purposes of our study, these were considered to be test false positives (as the reference standard of FFA was considered to have perfect sensitivity and specificity).

Our searches identified four health-technology assessment reports that included an assessment of OCT 
PHP

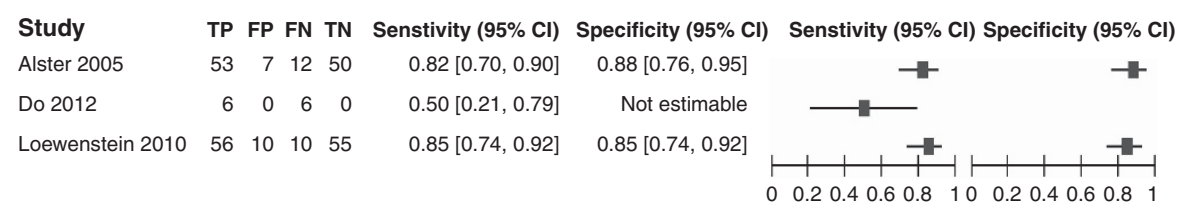

ICGA

$\begin{array}{lrrrrrr}\text { Study } & \text { TP } & \text { FP } & \text { FN } & \text { TN } & \text { Senstivity }(95 \% \text { Cl) } & \text { Specificity }(95 \% \text { Cl) } \\ \text { Cachulo 2011 } & 16 & 0 & 1 & 0 & 0.94[0.71,1.00] & \text { Not estimable } \\ \text { Fujii 1996 } & 11 & 12 & 2 & 7 & 0.85[0.55,0.98] & 0.37[0.16,0.62] \\ \text { Reichel 1995 } & 16 & 0 & 0 & 0 & 1.00[0.79,1.00] & \text { Not estimable } \\ \text { Torron 2002 } & 94 & 0 & 8 & 0 & 0.92[0.85,0.97] & \text { Not estimable }\end{array}$

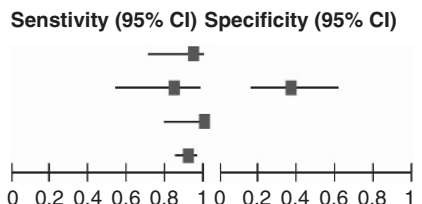

$\mathrm{PHP}=$ preferential hyperacuity perimeter; ICGA= indocyanine green angiography; $\mathrm{TP}=$ true positive; $\mathrm{FP}=$ false positive; $\mathrm{FN}=$ false negative; $\mathrm{TN}=$ true negative; $\mathrm{Cl}=$ confidence interval.

Figure 5 Individual study results for sensitivity and specificity.

in the detection of nAMD. ${ }^{38-41}$ The German report by Stürzlinger $e a^{39}$ concluded that although OCT yielded diagnostic findings in addition to FFA results, OCT could not replace FFA for initial diagnosis. The Belgian Health Care Knowledge Centre report, similar to this review, reported high sensitivity (96-97\%) and moderate specificity $(66 \%)$ for OCT. ${ }^{41}$ However, the Australian MSAC report concluded that due to the absence of a valid reference standard, the diagnostic accuracy of OCT could not be assessed. ${ }^{40}$ The report by the Medical Advisory Secretariat, Ontario, Canada also questioned the validity of FFA as a reference standard and presented conclusions that were based on expert consultations. ${ }^{38}$

In conclusion, we identified a relatively small number of studies, of variable quality, on the performance of OCT in the diagnosis of people newly presenting with a suspicion of nAMD. The available evidence suggests that although TD-OCT is a relatively sensitive test for the initial diagnosis of nAMD, it is of moderate specificity. Consequently, it should not be used as the only test to diagnose nAMD. The current evidence suggests that TDOCT should not replace the reference standard of FFA in the diagnosis of nAMD. Further research is required for evaluating the diagnostic performance of SD-OCT for nAMD.

\section{Conflict of interest}

The authors declare no conflict of interest.

\section{Acknowledgements}

This paper was based on a wider piece of research that was funded by the National Institute for Health Research Health Technology Assessment (NIHR HTA) Programme (project number 10/57/22) that will be published in full in Health Technology Assessment. The Health Services
Research Unit is core-funded by the Chief Scientist Office (CSO) of the Scottish Government Health and Social Care Directorates. The views and opinions expressed therein are those of the authors and do not necessarily reflect those of the HTA programme, NIHR, NHS, Department of Health or the CSO.

\section{References}

1 Brown DM, Michels M, Kaiser PK, Heier JS, Sy JP, Ianchulev T et al. Ranibizumab versus verteporfin photodynamic therapy for neovascular age-related macular degeneration: Two-year results of the ANCHOR study. Ophthalmology 2009; 116: 57-65.

2 Martin DF, Maguire MG, Fine SL, Ying GS, Jaffe GJ, Grunwald JE et al. Comparison of Age-related Macular Degeneration Treatments Trials (CATT) Research Group. Ranibizumab and bevacizumab for treatment of neovascular age-related macular degeneration: two-year results. Ophthalmology 2012; 119: 1388-1398.

3 Chakravarthy U, Harding SP, Rogers CA, Downes SM, Lotery AJ. the IVAN Study Investigators et al. Ranibizumab versus bevacizumab to treat neovascular age-related macular degeneration: one-year findings from the IVAN randomized trial. Ophthalmology 2012; 119: 1399-1411.

4 Rosenfeld PJ, Brown DM, Heier JS, Boyer DS, Kaiser PK, Chung CY et al. Ranibizumab for neovascular age-related macular degeneration. N Engl J Med 2006; 355: 1419-1431.

5 Macular Photocoagulation Study Group. Laser photocoagulation of subfoveal neovascular lesions in age-related macular degeneration. Results of a randomized clinical trial. Arch Ophthalmol 1991; 109: 1220-1231.

6 Macular Photocoagulation Study Group. Laser photocoagulation for juxtafoveal choroidal neovascularization. Five-year results from randomized clinical trials. Arch Ophthalmol 1994; 112: 500-509.

7 Treatment of age-related macular degeneration with photodynamic therapy (TAP) Study Group. Photodynamic therapy of subfoveal choroidal neovascularization in age-related macular degeneration with verteporfin: one-year results of 2 randomized clinical trials-TAP report. Arch Ophthalmol 1999; 117: 1329-1345. 
8 Age-related macular degeneration - Guidelines for management (document on the Internet)London: Royal College of Ophthalmologists; 2009 (accessed September 2013). URL http://www.rcophth.ac.uk/core/core_picker/ download.asp?id $=1185 \&$ filetitle $=$ Age $\%$.

9 Amercian Academy of Ophthalmology Retina PanelPreferred Practice Pattern Guidelines: Age-Related Macular Degeneration. San Fransisco: American Academy of Ophthalmology 2011, (accessed September 2013). URL http://www.aao.org/ppp.

10 Whiting PF, Rutjes AW, Westwood ME, Mallett S, Deeks JJ, Reitsma JB et al. QUADAS-2: a revised tool for the quality assessment of diagnostic accuracy studies. Ann Inte Med 2011; 155: 529-536.

11 Rutter CM, Gatsonis CA. A hierarchical regression approach to meta-analysis of diagnostic test accuracy evaluations. Stat Med 2001; 20: 2865-2884.

12 Alster Y, Bressler NM, Bressler SB, Brimacombe JA, Crompton RM, Duh YJ et al. Preferential Hyperacuity Perimeter (PreView PHP) for detecting choroidal neovascularization study. Ophthalmology 2005; 112: 1758-1765.

13 Cachulo L, Silva R, Fonseca P, Pires I, Carvajal-Gonzalez S, Bernardes $\mathrm{R}$ et al. Early markers of choroidal neovascularization in the fellow eye of patients with unilateral exudative age-related macular degeneration. Ophthalmologica 2011; 225: 144-149.

14 Chen S, Han M, Wang L. Indocyanine green angiography of exudative age-related macular degeneration. Chin Ophthalmic Res 2003; 21: 428-430.

15 Do DV, Gower EW, Cassard SD, Boyer D, Bressler NM, Bressler SB et al. Detection of new-onset choroidal neovascularization using optical coherence tomography: the AMD DOC Study. Ophthalmology 2012; 119: 771-778.

16 Fujii C, Inobe K, Sugimoto Y, Sugimoto A, Takahashi Y, Akagi $Y$. Indocyanine green angiographic findings in eyes with age-related macular degeneration. Folia Ophthalmol Jpn 1996; 47: 300-305.

17 Gomi F, Sawa M, Mitarai K, Tsujikawa M, Tano Y. Angiographic lesion of polypoidal choroidal vasculopathy on indocyanine green and fluorescein angiography. Graefes Arch Clin Exp Ophthalmol 2007; 245: 1421-1427.

18 Hughes EH, Khan J, Patel N, Kashani S, Chong NV. In vivo demonstration of the anatomic differences between classic and occult choroidal neovascularization using optical coherence tomography. Am J Ophthalmol 2005; 139: 344-346.

19 Khondkaryan A, Keane PA, Liakopoulos S, Walsh AC, Sadda SR. Comparison of optical coherence tomography and fluorescein angiography for the classification of neovascular age-related macular degeneration. Invest Ophthalmol Vis Sci 2009; 50: E-abstract 5259.

20 Kim SG, Lee SC, Seong YS, Kim SW, Kwon OW. Choroidal neovascularization characteristics and its size in optical coherence tomography. Yonsei Med J 2003; 44: 821-827.

21 Kozak I, Morrison VL, Clark TM, Bartsch DU, Lee BR, Falkenstein I et al. Discrepancy between fluorescein angiography and optical coherence tomography in detection of macular disease. Retina 2008; 28: 538-544.

22 Krebs I, Binder S, Stolba U, Krepler K, Zeiler F, Glittenberg C. The value of optical coherence tomography in diagnosis and therapy of age-related macular degeneration. Spektrum Augenheilkund 2007; 21: 33-38.

23 Liakopoulos S, Ongchin S, Bansal A, Msutta S, Walsh AC, Updike PG et al. Quantitative optical coherence tomography findings in various subtypes of neovascular age-related macular degeneration. Invest Ophthalmol Vis Sci 2008; 49 : 5048-5054.

24 Loewenstein A, Ferencz JR, Lang Y, Yeshurun I, Pollack A, Siegal $\mathrm{R}$ et al. Toward earlier detection of choroidal neovascularization secondary to age-related macular degeneration: multicenter evaluation of a preferential hyperacuity perimeter designed as a home device. Retina 2010; 30: 1058-1064.

25 Padnick-Silver L, Weinberg AB, Lafranco FP, Macsai MS. Pilot study for the detection of early exudative age-related macular degeneration with optical coherence tomography. Retina 2012; 32: 1045-1056.

26 Park SS, Truong SN, Zawadzki RJ, Alam S, Choi SS, Telander DG et al. High-resolution Fourier-domain optical coherence tomography of choroidal neovascular membranes associated with age-related macular degeneration. Invest Ophthalmol Vis Sci 2010; 51: 4200-4206.

27 Parravano M, Varano M, Virgili G. Integrated imaging approach in RAP diagnosis. Acta Ophthalmol (Copenh) 2012; 90(S249): Abstract 4426.

28 Reichel E, Duker JS, Puliafito CA. Indocyanine green angiography and choroidal neovascularization obscured by hemorrhage. Ophthalmology 1995; 102: 1871-1876.

29 Salinas-Alaman A, Garcia-Layana A, Maldonado MJ, Sainz-Gómez C, Alvárez-Vidal A. Using optical coherence tomography to monitor photodynamic therapy in age related macular degeneration. Am J Ophthalmol 2005; 140: 23-28.

30 Sandhu SS, Talks SJ. Correlation of optical coherence tomography, with or without additional colour fundus photography, with stereo fundus fluorescein angiography in diagnosing choroidal neovascular membranes. $\mathrm{Br} \mathrm{J}$ Ophthalmol 2005; 89: 967-970.

31 Silva R, Cachulo ML, Fonseca P, Bernardes R, Nunes S, Vilhena $\mathrm{N}$ et al. Age-related macular degeneration and risk factors for the development of choroidal neovascularisation in the fellow eye: a 3-year follow-up study. Ophthalmologica 2011; 226: 110-118.

32 Sulzbacher F, Kiss C, Munk M, Deak G, Sacu S, Schmidt-Erfurth U. Diagnostic evaluation of type 2 (classic) choroidal neovascularization: optical coherence tomography, indocyanine green angiography, and fluorescein angiography. Am J Ophthalmol 2011; 152: 799-806; e1.

33 Talks J, Koshy Z, Chatzinikolas K. Use of optical coherence tomography, fluorescein angiography and indocyanine green angiography in a screening clinic for wet age-related macular degeneration. Br J Ophthalmol 2007; 91: 600-601.

34 Torron FB, Melcon SF, Ferrer N, Ruiz Moreno O, Honrubia López FM. Indocyanine green angiography and subretinal neovascularization. Patterns in age related macular degeneration. Arch Soc Esp Oftalmol 2001; 76: 221-228.

35 Torron FB, Perez O, Melcon SF, Ferrer Novella E, Ruiz-Moreno O, Honrubia López FM. Dynamic angiography in age related macular degeneration. Arch Soc Esp Oftalmol 2002; 77: 353-359.

36 Leeflang MM, Deeks JJ, Gatsonis C, Bossuyt PM. Cochrane Diagnostic Test Accuracy Working Group. Systematic reviews of diagnostic test accuracy. Ann Intern Med 2008; 149: 889-897.

37 Glasziou P, Irwig L, Deeks JJ. When should a new test become the current reference standard? Ann Intern Med 2008; 149: 816-822

38 Optical coherence tomography for age-related macular degeneration and diabetic macular edema: and 
evidence-based analysisOntario Health Technology Assessment Series 2009;9(13) (document on the Internet). Ontario: Medical Advisory Secretariat (MAS) 2009, (accessed September 2013). URL http://www.health.gov.on.ca/ english/providers/program/mas/tech/reviews/pdf/ rev_oct_20090925.pdf.

39 Stürzlinger H, Fröschl B, Genser D. Evaluation of optical coherence tomography in the diagnosis of age related macular degeneration compared with fluorescence angiography (document on the Internet). Cologne: The German Agency for Health Technology Assessment (DAHTA) 2007, (accessed September 2013). URL http:/ / portal.dimdi.de/de/hta/hta_berichte/hta149_ bericht_de.pdf.
40 Optical coherence tomography MSAC application 1116 (document on the Internet) Canberra: Medical Services Advisory Committee (MSAC); 2009 (accessed September 2013). URL http://www.msac.gov.au/internet/msac/publishing. nsf/Content/115CC907F00447B3CA2575AD0082FD6C/\$File/ $1116 \% 20$ Optical $\% 20$ Coherence $\%$ 20Tomography $\% 20$ Report.pdf.

41 Van den Bruel A, Gailly J, Vijens F, Devriese S. Guidance for the use of five ophthalmic tests in clinical practice KCE reports $71 \mathrm{C}$ (document on the Internet). Brussels: The Belgian Health Care Knowledge Centre (KCE) 2008, (accessed September 2013). URL https://kce.fgov.be/ publication/report/guidance-for-the-use-of-fiveophthalmic-tests-in-clinical-practice.

Supplementary Information accompanies this paper on Eye website (http://www.nature.com/eye) 